\title{
Expectativas de carreira em acadêmicos do mestrado profissional em administração: estudo em uma instituição comunitária de ensino superior
}

\section{Career expectations in academic professional master's} in administration: study in a community college

\author{
Rosana Marques da Silva Rampazzo \\ Universidade do Vale do Itajaí (UNIVALI) \\ email:marques@univali.br
}

\section{lúri Novaes Luna}

Universidade Federal de Santa Catarina (UFSC)

email: iuri.luna@ufsc.br

\author{
Gabriela Keller de Moura \\ Universidade do Vale do Itajaí (UNIVALI) \\ email:gabrielakellerm@hotmail.com
}

\section{RESUMO}

O estudo objetivou analisar expectativas de carreira dos acadêmicos de um programa de mestrado profissional em administração em relação à entrada e término do mestrado e suas concepções sobre sucesso na carreira, bem como verificar associações entre variáveis de carreira e variáveis sociodemográficas e educacionais. Caracteriza-se como pesquisa de método misto, exploratório-descritiva, realizada com 62 mestrandos que responderam a um questionário. Os dados foram tratados pela estatística descritiva e inferencial e análise de conteúdo. Os resultados indicaram expectativas de carreira relacionadas à prática profissional, ao alcance de objetivos pessoais e profissionais, com destaque à carreira docente e desenvolvimento de competências. Quanto ao sucesso na carreira, $69,4 \%$ o associaram à dimensão subjetiva, $4,8 \%$ a fatores objetivos. De acordo com o teste qui-quadrado, não foram observadas associações significativas entre variáveis de carreira e as demais variáveis investigadas. O mestrado profissional representa desenvolvimento na carreira e transição parcial ou total à carreira acadêmica.

Palavras-Chave: Mestrado profissional, expectativa profissional, sucesso na carreira, administração.

\section{ABSTRACT}

The study aimed to analyze career expectations of academics from a professional master's program in administration in relation to entering and completing the master's degree, and their conceptions of career success, as well as verifying associations between career variables and socio-demographic and educational variables. It is characterized as a mixed-method, exploratory-descriptive research, carried out with 62 master's students who responded to the questionnaire. The data were processed using the descriptive and inferential statistics and content analysis. The results indicated career expectations related to professional practice, the achievement of personal and professional goals, with emphasis on the teaching career and competence development. Regarding career success, $69.4 \%$ associated it with the subjective dimension, $4.8 \%$ with objective factors. According to the chi-square test, no significant associations were observed between career variables and the other investigated variables. The professional master's represents career development and a partial or complete transition to an academic career.

Key-words: Professional master's, professional expectation, career success, administration. 


\section{INTRODUCTION}

As mudanças observadas nas últimas décadas no mundo de trabalho ensejaram uma série de estudos sobre o tema carreira, resultando em novos modelos teóricos, com destaque aos processos de desenvolvimento dos indivíduos no decorrer de suas trajetórias profissionais. (BARROS, CAPPELLE e GUERRA, 2019; SEWAYBRICKER, 2018; SILVA e ANDRADE, 2019). Associada aos novos modelos de carreira (BENDASSOLLI, 2009), a educação continuada tornou-se uma exigência para o desenvolvimento profissional e, nesse contexto, diversas modalidades de formação emergiram ou se fortaleceram, tais como os mestrados profissionais (MARQUEZAN e SAVEGNAGO, 2020).

O Mestrado Profissional foi reconhecido pela Portaria CAPES nº 080, de 16 de dezembro de 1998 (BRASIL, 1998), que revogou a Portaria CAPES n ${ }^{\circ}$ 47, de 17/10/95 (BRASIL, 1995). Essa nova portaria considerou a necessidade de profissionais pós-graduados aptos a elaborar novas técnicas e processos, com desempenho diferenciado de egressos dos cursos de mestrado que visem preferencialmente o aprofundamento de conhecimentos ou técnicas de pesquisa científica, tecnológica ou artística.

Os objetivos do mestrado profissional envolvem a capacitação profissional, o atendimento de demandas sociais, organizacionais, profissionais e do mercado de trabalho; a transferência de conhecimentos à sociedade com vistas ao desenvolvimento nacional, regional ou local. Ainda, a promoção da articulação profissional com organizações públicas e privadas, com foco em sua eficácia e eficiência; aumento da competitividade e produtividade, conforme Art. $2^{\circ}$ da Portaria CAPES no 389, de 23/03/2017.

Desde a sua regulamentação no país, a procura pelo mestrado profissional cresceu de forma significativa, sendo que em 2008 havia 9.073 matriculados, enquanto em 2017 esse número aumentou para 37.568. Quanto à titulação, em 2008 o Brasil possuía 2.654 mestres e, em 2017, 10.841 profissionais pós-graduados no mestrado profissional (GEOCAPES, 2020). Tais dados indicam acréscimo de mais de $400 \%$ em uma década. Especificamente em Santa Catarina, em 2017, o número de matriculados em cursos de mestrado profissional era de 1.264, sinalizando a necessidade de maiores estudos com esse público.

Destarte, a entrada em um programa de mestrado apresenta-se como uma possível estratégia de carreira para lidar com os desafios impostos pelo mercado de trabalho contemporâneo. A escolha por cursar um programa de pós-graduação stricto sensu pode ser motivada pelo interesse em desenvolver uma carreira acadêmica na educação superior ou em institutos de pesquisa como docente e pesquisador (GEREMIA, LUNA e SANDRINI, 2015). Pode, também, se configurar como uma forma do indivíduo atrasar a entrada no mundo do trabalho por não saber o que fazer profissionalmente ou em decorrência do fenômeno do alongamento da escolarização diante do estreitamento de oportunidades profissionais (MATTOS, 2011).

Ainda, por estarem, muitas vezes, vinculados a processos de transição de carreira, os cursos de mestrado profissional têm sido procurados por profissionais inseridos no mundo do trabalho, como forma de aumentar o autoconhecimento e redirecionar a carreira profissional (MACIEL e NOGUEIRA, 2012). Diante desse cenário, este estudo objetivou analisar as expectativas de carreira dos acadêmicos de um programa de mestrado profissional em administração em relação à entrada e término do mestrado e suas concepções sobre sucesso na carreira. Adicionalmente, buscou verificar associações entre variáveis sociodemográficas e educacionais e variáveis relacionadas às expectativas de carreira.

Inicialmente, apresenta-se a revisão teórica sobre estudos relacionados a programas de mestrado profissional, com ênfase na área da administração. $\mathrm{Na}$ sequência, discutem-se os conceitos de expectativa de carreira e sucesso na carreira, assim como pesquisas sobre tais construtos, envolvendo diferentes públicos. Os participantes, instrumentos e procedimentos da pesquisa são descritos no método. Em seguida, são apresentados os principais resultados, a discussão e as considerações finais. 


\section{REVISÃO TEÓRICA}

\subsection{Mestrado Profissional}

Os mestrados profissionais, por sua especificidade, apresentam-se como uma alternativa de formação continuada que associa as demandas do trabalho ao mundo acadêmico, mediante o aprimoramento acadêmico e profissional, bem como os processos de inovação e solução de problemas provenientes de organizações públicas e privadas (MARQUEZAN e SAVEGNAGO, 2020). Com o crescimento dessa modalidade de educação no Brasil observa-se o interesse por estudos sobre esse tema, tendo como participantes mestrandos das áreas da Educação, Ciências da Saúde e Administração.

Tais investigações focaram o levantamento das diretrizes para elaboração de trabalhos de conclusão do mestrado e o perfil dos mestrandos (FERREIRA et al., 2015; RADÜNZ, 2015); o nível da qualificação dos profissionais que saem do mestrado, os objetivos do mestrado e a análise da intercambistas (ALMEIDA et al., 2017); a intersubjetividade na vida profissional dos mestrandos (MAMEDE e ABBAD, 2018; SILVA, 2017); percepção dos egressos sobre o impacto do mestrado profissional, como uma modalidade de formação continuada, na vida profissional e acadêmica (MARQUEZAN e SAVEGNAGO, 2020; SCOCHI et al., 2015); a influência do mestrado no desenvolvimento de propostas educacionais (NÓBREGA, 2018; SANTOS, 2018; LIBERMAN, 2015) e discutiram questões relacionadas a enfermeiros mestrandos (ABRAHAMSEN, 2019; FERREIRA et al., 2015).

Sobre os mestrados profissionais na área da administração, destacam-se quatro investigações com egressos dos programas. O primeiro estudo objetivou identificar os ganhos sociais alcançados por alunos egressos do Mestrado Profissional em Gestão e Estratégia em Negócios da UFRRJ (MACIEL e NOGUEIRA, 2012). A pesquisa de Guimarães (2018) visou compreender os fatores que influenciaram a escolha pelo mestrado profissional em administração da FVG EBAPE. Já o terceiro estudo investigou se as diretrizes para conclusão dos trabalhos do mestrado profissional da Faculdade de Economia, Administração e Contabilidade da Universidade de São Paulo eram utilizadas pelos alunos em seus projetos
(KRAKAUER, MARQUES e ALMEIDA, 2018). A pesquisa de Paixão e Hastenreiter Filho (2014) analisou, com base na visão de 124 egressos de um curso de mestrado profissional em Administração (MPA) de uma universidade brasileira, os impactos em suas competências e habilidades, renda e carreira.

Verifica-se que as publicações a respeito dos mestrados profissionais se concentram no perfil dos alunos, nos temas de interesse e em aspectos relacionados à satisfação com o programa. Não foram encontrados estudos com alunos de programas de mestrado profissional que abordassem as expectativas de carreira, englobando questões relacionadas ao sucesso na carreira.

\subsection{Expectativas de Carreira}

As expectativas de carreira são compreendidas como crenças pessoais sobre o futuro profissional, idealizações que os indivíduos possuem a respeito do porvir de suas carreiras, que se encontram associadas ao significado de sucesso na carreira. Por meio de tais crenças, vinculadas a determinados valores pessoais, cada profissional define o que é importante para si. Ressalta-se que o sucesso na carreira, caracterizado como uma avaliação positiva dos resultados psicológicos e materiais derivados da relação do indivíduo com o trabalho, envolve uma dimensão objetiva, externamente verificada, e uma dimensão subjetiva, internamente percebida (OLIVEIRA et al., 2019). A primeira dimensão compreende características extrínsecas, como renda, estabilidade profissional, promoções de carreira e status profissional. A segunda refere-se à avaliação pessoal de sucesso com base em percepções de resultados de carreira intrínsecos e extrínsecos, e se encontra vinculada à satisfação com a carreira e com a natureza do trabalho em si (BONASSI e WOLTER, 2002; DRIES, 2011; NG e FELDMAN, 2014; SILVA e MARQUES, 2001).

À medida que novos modelos de carreira se tornam mais presentes em um contexto de trabalho em transformação, aumenta a participação dos valores pessoais e das narrativas individuais nas expectativas de carreira e nas concepções sobre o que significa ser bem-sucedido na carreira (DRIES, 2011; SAVICKAS, 2012). A natureza multidimensional do construto sucesso na carreira foi confirmada nos estudos 
empíricos de Oliveira (2014) e Oliveira et al. (2019) com recém-formados no processo de transição universidade-trabalho. Tanto os indicadores subjetivos relacionados à confiança no futuro, à elaboração de planos de carreira, à construção da identidade profissional, à adaptação ao trabalho e à satisfação com a trajetória de carreira; quanto indicadores objetivos, representados por resultados tangíveis, como conseguir trabalho na área de formação, independência financeira e reconhecimento social, estiveram envolvidos na percepção de sucesso de carreira.

Investigações nacionais e internacionais realizadas nos últimos anos sobre expectativas de carreira abordam o tema com diferentes públicos, tais como universitários graduandos (ABRAHAMSEN, 2019; LENT et al., 2017); recém-egressos de universidades (FERREIRA et al., 2015; GUIMARÃES, 2018; MACIEL e NOGUEIRA, 2012; SILVA, 2015; SILVEIRA, 2016); trabalhadores já inseridos no mercado de trabalho e em organizações (FRENKEL e BEDNALL, 2016; ZHANG et al., 2018); e determinados profissionais, como professores (BAGLAMA e UZUNBOYLU, 2017). Já com o público pós-graduando (lato sensu e stricto sensu), os estudos envolvem alunos do mestrado (HENSTRA e MCGOWAN, 2016); doutorado (GU, LEVIN e LUO, 2018), pós-doutorado (VAN DER WEIJDEN et al., 2016) e, especificamente, residentes de medicina (ALSTON et al., 2018; HAN et al., 2019).

Os objetivos dos referidos estudos envolveram desenvolvimento e validação de escalas sobre expectativas de carreira em organizações e relações de expectativas de carreira com variáveis organizacionais vinculadas à gestão de pessoas. Incluíram, ainda, pesquisas sobre expectativas de egressos a respeito da inserção no mercado de trabalho e desenvolvimento de carreira, motivações para permanecer ou abandonar a profissão, empregos em um contexto de incerteza, e expectativas quanto ao envelhecimento na carreira e aposentadoria. No que se refere às expectativas de carreira de pós-graduandos, os estudos investigaram aspectos sobre os benefícios de seguir uma carreira pública, se as expectativas de carreira mudam ao longo do tempo, os planos e projeções de carreira, as motivações e expectativas profissionais (ALSTON et al., 2018; GU, LEVIN e LUO, 2018; HAN et al., 2019; HENSTRA e MCGOWAN, 2016; VAN DER WEIJDEN et al., 2016).

\section{MÉTODO}

A investigação foi realizada por intermédio de métodos mistos, sendo que os dados quantitativos e qualitativos foram coletados concomitantemente, ou seja, a implementação foi simultânea, não sequencial (CRESWELL, 2007). A escolha por esta abordagem deve-se à possibilidade de integrar informações de diferentes naturezas, o que permite uma exploração mais ampla do fenômeno estudado, uma vez que não foram identificados estudos específicos sobre o tema da presente investigação com acadêmicos de programas de mestrado profissional em administração. Desta forma, este estudo caracteriza-se como exploratório-descritivo (SAMPIERI, COLLADO e LUCIO, 2010), pois buscou apresentar novas perspectivas sobre o tema e descrever as principais características relacionadas às expectativas de carreira e ao sucesso na carreira no público investigado. $\mathrm{O}$ projeto foi submetido ao Comitê de Ética em Pesquisa da Universidade, recebendo parecer favorável.

\subsection{Participantes}

A população do estudo foi alunos do programa de mestrado profissional em administração de uma universidade comunitária localizada em Santa Catarina. De acordo com o Projeto Pedagógico do referido programa, este destina-se a profissionais formados preferencialmente nos cursos de graduação na área das ciências sociais aplicadas. É proposto, ainda, a consultores, a profissionais graduados atuantes na gestão de empresas e instituições, bem como empreendedores.

A amostra foi composta por 62 acadêmicos matriculados regularmente no referido programa de mestrado profissional em administração, que iniciaram o curso nos primeiros ou segundos semestres dos anos de 2017, 2018 e 2019. Assim, o estudo envolveu todos os acadêmicos de seis turmas do mestrado profissional que se encontravam em sala de aula no momento da coleta e que, após o convite e as devidas explicações sobre a pesquisa, demonstr- 
aram interesse em participar. Desse modo, a amostra, embora não probabilística (RICHARDSON, 1999), alcançou $86 \%$ do número total de matriculados das respectivas turmas.

\subsection{Instrumento e procedimentos de coleta de dados}

Pesquisas sobre processos de construção de carreiras na contemporaneidade, que discutem transições, expectativas e sucesso na carreira, têm sido desenvolvidas mediante métodos quantitativos e qualitativos, considerando as dimensões objetiva e subjetiva que compõem os construtos. Quando o intuito é conhecer os significados atribuídos pelos participantes a partir de suas narrativas sobre o tema, geralmente um número reduzido de pessoas é investigado, por meio de grupos focais (OLIVEIRA et al., 2019) e entrevistas (MACIEL e NOGUEIRA, 2012; OLIVEIRA, KILIMNIK e OLIVEIRA, 2013). Todavia, para ampliar o número de participantes mantendo a possibilidade de realizar análises qualitativas, além de quantitativas, questionários com perguntas abertas e fechadas têm se mostrado adequados (GUIMARÃES, 2018; MARQUEZAN e SAVEGNAGO, 2020).

$\mathrm{Na}$ presente investigação utilizou-se como instrumento de coleta de dados um questionário misto contendo 18 questões, sendo 11 abertas e sete fechadas. As perguntas do instrumento coletaram informações sobre a caracterização dos participantes, questões educacionais e profissionais, expectativas de carreira e sucesso na carreira. Antes do início da coleta foi realizado teste piloto com oito mestrandos, para os ajustes necessários no instrumento. Na sequência, o questionário foi aplicado de forma coletiva e presencial, nos períodos de aula, com a autorização do professor da disciplina, após a assinatura do Termo de Consentimento Livre Esclarecido (TCLE) por todos os respondentes. O preenchimento do questionário teve duração aproximada de 30 minutos.

\subsection{Procedimentos de análise de dados}

Os dados referentes às questões fechadas foram tabulados por meio de distribuição de frequência simples e relativa. As informações provenientes das questões abertas foram tratadas pela técnica de análise de conteúdo de Bardin (2016), sendo organizadas em três categorias e seis subcategorias, definidas à priori, ao considerar os objetivos da pesquisa e o referencial teórico sobre o tema, descritas no quadro 1.

Cabe destacar que variáveis sociodemográficas e educacionais se relacionam a diferentes variáveis de carreira, conforme literatura. Desta forma, este estudo investigou, por meio de estatística inferencial utilizando o teste qui-quadrado (FIELD, 2009), a possível existência de associações estatisticamente significativas entre variáveis sociodemográficas (geração, sexo, estado civil, ter ou não filhos), educacionais (decisão pelo mestrado no período da graduação, ter cursado

Quadro 1 Descrição operacional das categorias e subcategorias

\begin{tabular}{l|l}
\multicolumn{1}{c|}{ Categorias } & \multicolumn{1}{c}{ Subcategorias } \\
\hline \multirow{2}{*}{$\begin{array}{l}\text { Expectativas em relação à entrada no } \\
\text { mestrado profissional }\end{array}$} & $\begin{array}{l}\text { Desenvolvimento de competências: aprofundamento de conhecimentos e desenvolvimento de } \\
\text { competências comportamentais. }\end{array}$ \\
\cline { 2 - 2 } & $\begin{array}{l}\text { Prática profissional: ampliação da prática profissional e melhoria do desempenho na atual profis- } \\
\text { são/carreira }\end{array}$ \\
\hline \multirow{2}{*}{$\begin{array}{l}\text { Expectativas em relação ao término do } \\
\text { mestrado profissional }\end{array}$} & $\begin{array}{l}\text { Objetivos pessoais/profissionais: reconhecimento pessoal e profissional, aumento de renda e } \\
\text { satisfação pessoal. }\end{array}$ \\
\cline { 2 - 2 } & $\begin{array}{l}\text { Prática profissional: transição parcial ou total para a docência, ampliação profissional em sua área } \\
\text { de atuação e desempenho na atual profissão/carreira. }\end{array}$ \\
\hline \multirow{2}{*}{$\begin{array}{l}\text { Expectativas em relação a sucesso na } \\
\text { carreira }\end{array}$} & $\begin{array}{l}\text { Dimensão subjetiva: aspectos associados à natureza do trabalho, como gostar e estar feliz com o } \\
\text { que faz, reconhecimento e crescimento profissional. }\end{array}$ \\
\cline { 2 - 3 } & $\begin{array}{l}\text { Dimensão objetiva: aspectos associados à recompensas advindas do trabalho, como estabilidade } \\
\text { financeira, remuneração satisfatória e ter mais tempo. }\end{array}$
\end{tabular}


pós-graduação lato sensu) e variáveis relacionadas às expectativas de carreira (ao entrar no mestrado, ao término do mestrado e sucesso na carreira). Buscou-se, assim, informações adicionais que possam contribuir para a compreensão das expectativas de carreira dos participantes do presente estudo.

\section{RESULTADOS}

As informações sociodemográficas dos participantes podem ser observadas na Tabela 1 . Verificou-se que 50\% dos participantes possuem entre 27 e 46 anos, sendo que a média das idades dos participantes que responderam essa questão é de 35,2. Dessa forma, a maioria pertence às gerações $Y$ (nascidos entre 1980-2000) e X (nascidos entre 1965-1980). A grande parte deles é do sexo masculino, encontra-se casada ou em união estável e sem filhos. Praticamente, a metade deles reside nas cidades de Itajaí e Balneário Camboriú, ambas em Santa Catarina. O resultado do teste qui-quadrado indicou diferenças estatisticamente significativas na amostra entre as gerações e o fato de ter ou não filhos, sendo que os participantes da geração $Y$ tendem a não ter filhos em comparação aos das demais gerações $(p=0,006)$. O teste revelou, ainda, uma associação entre local de residência e formação em cursos lato sensu ( $\mathrm{p}=0,002$ ), sendo que os acadêmicos investigados que residem em outras cidades possuem mais cursos de pós-graduação em comparação aos que moram em Itajaí e Balneário Camboriú/SC. Não foram encontradas associações estatisticamente significativas entre as variáveis de carreira e as variáveis sociodemográficas avaliadas, a saber: geração $(\mathrm{p}=0,81)$; sexo $(\mathrm{p}=, 064)$ estado civil $(\mathrm{p}=0,34)$ e se possui ou não filhos $(\mathrm{p}=0,73)$. Assim, é possível sugerir que na amostra investigada não houve diferenças significativas nas expectativas de carreira em relação a essas variáveis sociodemográficas.

Os dados da Tabela 2, sobre questões educacionais e profissionais, revelam que $3 /{ }_{4}$ dos participantes são graduados na área de Ciências Sociais Aplicadas, prevalecendo os cursos de Administração $(n=13)$, Logística $(n=08)$, Comércio Exterior $(n=06)$ e Ciências Contábeis $(n=05)$. Poucos foram bolsistas durante a graduação e cursaram mais do que uma graduação. Destaca-se que grande parte deles cursou
Tabela 1 Dados sociodemográficos

\begin{tabular}{|c|c|c|c|}
\hline & & $\mathbf{N}$ & $\%$ \\
\hline Idade & $\begin{array}{l}\text { Até } 26 \text { anos } \\
27 \text { a } 36 \text { anos } \\
37 \text { a } 46 \text { anos } \\
\text { Acima de } 47 \text { anos } \\
\text { Em branco }\end{array}$ & $\begin{array}{c}10 \\
21 \\
13 \\
5 \\
13\end{array}$ & $\begin{array}{c}16,1 \\
29 \\
21 \\
8,1 \\
25,8\end{array}$ \\
\hline Geração & $\begin{array}{l}X \\
Y \\
Z \\
\text { Em branco }\end{array}$ & $\begin{array}{c}12 \\
32 \\
5 \\
13\end{array}$ & $\begin{array}{c}19,4 \\
51,6 \\
8,1 \\
21\end{array}$ \\
\hline Sexo & $\begin{array}{l}\text { Masculino } \\
\text { Feminino }\end{array}$ & $\begin{array}{l}42 \\
20\end{array}$ & $\begin{array}{l}67,7 \\
32,3\end{array}$ \\
\hline Estado civil & $\begin{array}{l}\text { Casado / união estável } \\
\text { Solteiro } \\
\text { Divorciado }\end{array}$ & $\begin{array}{c}37 \\
22 \\
3\end{array}$ & $\begin{array}{c}59,7 \\
35,5 \\
4,8\end{array}$ \\
\hline Filhos & $\begin{array}{l}\text { Sim } \\
\text { Não } \\
\text { Em branco }\end{array}$ & $\begin{array}{c}24 \\
37 \\
1\end{array}$ & $\begin{array}{r}38,7 \\
59,7 \\
1,6\end{array}$ \\
\hline Moradia & $\begin{array}{l}\text { Com companheiro } \\
\text { Com os pais } \\
\text { Sozinho } \\
\text { Com amigos } \\
\text { Em branco }\end{array}$ & $\begin{array}{l}37 \\
15 \\
6 \\
3 \\
1\end{array}$ & $\begin{array}{c}59,7 \\
24,2 \\
9,7 \\
4,8 \\
1,6\end{array}$ \\
\hline $\begin{array}{l}\text { Cidade em } \\
\text { que reside }\end{array}$ & $\begin{array}{l}\text { Itajaí } \\
\text { Balneário Camboriú } \\
\text { Outras (SC; PR; RS) }\end{array}$ & $\begin{array}{l}15 \\
15 \\
32\end{array}$ & $\begin{array}{l}24,2 \\
24,2 \\
51,6\end{array}$ \\
\hline
\end{tabular}

Fonte: Dados da pesquisa.

especialização ou MBA, que um pouco mais da metade sinalizou que o mestrado já era uma opção desde a graduação e a grande maioria trabalha concomitante ao mestrado. Aproximadamente $1 / 4$ atua em cargo de gerência, $1 / 4$ como proprietário do negócio ou autônomo e quase $1 / 4$ como servidor público.

Os dados revelaram diferenças significativas no que se refere ao mestrado ser uma opção aos respondentes já na graduação $(\mathrm{p}=0,02)$, sendo que os homens tenderam a responder que o mestrado não era uma opção naquela época. O teste qui-quadrado não revelou associações estatisticamente significativas entre as variáveis de carreira e as variáveis educacionais avaliadas, a saber: cursado pós-graduação lato sensu ( $\mathrm{p}=0,72)$ e o mestrado ser uma opção logo após a graduação $(p=0,57)$. Sugere-se que não houve diferenças significativas em relação às expectativas de carreira, no que se refere a tais variáveis educacionais.

Informações relativas às expectativas de carreira e concepções de sucesso na carreira são sintetizadas 
Tabela 2 Dados educacionais e profissionais

\begin{tabular}{|c|c|c|c|}
\hline & & $\mathbf{N}$ & $\%$ \\
\hline Graduação & $\begin{array}{l}\text { Ciências Sociais Aplicadas } \\
\text { Ciências da Saúde } \\
\text { Ciências Exatas } \\
\text { Outros } \\
\text { Em branco }\end{array}$ & $\begin{array}{l}47 \\
3 \\
5 \\
4 \\
3\end{array}$ & $\begin{array}{r}75,8 \\
4,8 \\
8,1 \\
6,5 \\
4,8\end{array}$ \\
\hline $\begin{array}{l}\text { Bolsista em } \\
\text { Iniciação } \\
\text { Científica }\end{array}$ & $\begin{array}{l}\text { Sim } \\
\text { Não }\end{array}$ & $\begin{array}{c}9 \\
53\end{array}$ & $\begin{array}{l}14,5 \\
85,5\end{array}$ \\
\hline $\begin{array}{l}\text { Cursos de } \\
\text { graduação }\end{array}$ & $\begin{array}{l}1 \\
\text { Mais de } 1 \\
\text { Em branco }\end{array}$ & $\begin{array}{c}52 \\
9 \\
1\end{array}$ & $\begin{array}{c}83,9 \\
14,5 \\
1,6\end{array}$ \\
\hline $\begin{array}{l}\text { Especializa- } \\
\text { ções }\end{array}$ & $\begin{array}{l}\text { Sim } \\
\text { Não } \\
\text { Em branco }\end{array}$ & $\begin{array}{l}40 \\
12 \\
10\end{array}$ & $\begin{array}{l}64,5 \\
19,4 \\
16,1\end{array}$ \\
\hline $\begin{array}{l}\text { Mestrado } \\
\text { logo após } \\
\text { graduação } \\
\text { como opção }\end{array}$ & $\begin{array}{l}\text { Sim } \\
\text { Não }\end{array}$ & $\begin{array}{l}33 \\
19\end{array}$ & $\begin{array}{l}53,2 \\
46,8\end{array}$ \\
\hline $\begin{array}{l}\text { Trabalha } \\
\text { concomitante } \\
\text { ao Mestrado }\end{array}$ & $\begin{array}{l}\text { Sim } \\
\text { Não }\end{array}$ & $\begin{array}{c}55 \\
7\end{array}$ & $\begin{array}{l}88,7 \\
11,3\end{array}$ \\
\hline $\begin{array}{l}\text { Cargo/ } \\
\text { Posição } \\
\text { Profissional }\end{array}$ & $\begin{array}{l}\text { Direção/Gerência } \\
\text { Professor } \\
\text { Propriet./Autônomo/Consultor } \\
\text { Servidor Público } \\
\text { Outros } \\
\text { Em branco }\end{array}$ & $\begin{array}{c}16 \\
8 \\
15 \\
2 \\
14 \\
7\end{array}$ & $\begin{array}{r}25,8 \\
12,9 \\
24,2 \\
3,2 \\
22,6 \\
11,3\end{array}$ \\
\hline
\end{tabular}

Fonte: Dados da pesquisa.

na Tabela 3. Os dados indicam que no momento do ingresso no mestrado profissional muitos participantes tinham a expectativa exclusiva de desenvolver determinadas competências pessoais e profissionais, tais como aprofundar/adquirir conhecimentos, desenvolver o pensamento crítico, ampliar ou desenvolver network, crescimento pessoal e profissional, amadurecimento e transformação pessoal e profissional. Expectativas exclusivas relacionadas à prática profissional, por sua vez, que incluem a possibilidade de abrir novos caminhos profissionais por meio da docência e a aplicação dos conhecimentos na prática, embora já estivessem presentes no momento do ingresso no mestrado, apareceram com maior destaque no momento do término no mestrado. Ainda, como expectativas ao término do mestrado, os respondentes apontaram atender objetivos pessoais e/ ou profissionais, com vistas à realização pessoal e ao reconhecimento profissional. Destaca-se que $41,9 \%$
Tabela 3 Expectativas de carreira

\begin{tabular}{l|l|c|c}
\hline & & N & $\%$ \\
\hline Ao entrar no & Desenv. de Competências & 20 & 32,3 \\
mestrado & Prática profissional & 13 & 21 \\
& Ambos & 26 & 41,9 \\
& Em branco & 3 & 4,8 \\
\hline \multirow{2}{*}{ Ao término } & Prática Profissional & 44 & 71 \\
do mestrado & Objetivos pessoais / profis. & 11 & 17,7 \\
& Ambos & 7 & 11,3 \\
\hline \multirow{2}{*}{ Sucesso na } & Dimensão Subjetiva & 43 & 69,4 \\
carreira & Dimensão Objetiva & 3 & 4,8 \\
& Ambos & 14 & 22,6 \\
& Em branco & 2 & 3,2 \\
\hline
\end{tabular}

Fonte: Dados da pesquisa.

dos respondentes, ao escolher o mestrado, vislumbravam tanto o desenvolvimento de competências quanto o aperfeiçoamento e a ampliação da prática profissional.

Quanto aos significados relacionados ao sucesso na carreira, também apresentados na Tabela 3, a maior parte dos respondentes evidenciou, exclusivamente, a dimensão subjetiva, por meio de respostas associadas à natureza e ao conteúdo do trabalho em si, com destaque para as expressões "felicidade no trabalho", "gostar do que faz" e "ser reconhecido". Menos do que $5 \%$ dos participantes indicaram exclusivamente a dimensão objetiva do sucesso da carreira, com respostas relacionadas a indicadores que não se referiram diretamente ao conteúdo do próprio trabalho, tais como estabilidade financeira, remuneração compatível e jornada de trabalho. Observa-se que quase $1 / 4$ dos respondentes, ao pensar sobre os significados do sucesso na carreira, descreveram indicadores relacionados a ambas as dimensões, subjetiva e objetiva.

\section{DISCUSSÃO}

Ao analisar as informações de caracterização da amostra investigada, revelam profissionais com maior experiência no mundo do trabalho ( $88,7 \%$ trabalham) que, de modo geral, não cursaram o mestrado logo após a graduação $(53,2 \%)$, considerando que $64,5 \%$ haviam cursado uma especialização ou MBA antes da entrada no mestrado profissional em Administração. Observa-se que esses dados são semelhantes à de 
outros estudos sobre o tema, como o de Guimarães (2018), cujo público-alvo envolveu egressos de dois mestrados profissionais em Administração. $\mathrm{O}$ autor descreveu a prevalência do sexo masculino (70\%), casado ou em união estável (66\%), com idade entre 31 e 60 anos e graduados em cursos das Ciências Sociais (50\%), principalmente Administração e Economia.

O teste qui-quadrado revelou que os acadêmicos residentes em outras cidades realizaram mais cursos lato sensu em comparação aos que moram nas cidades litorâneas de Itajaí e Balneário Camboriú/SC. Este fato pode ser reflexo da pequena quantidade de cursos de pós-graduação stricto sensu em cidades interioranas de Santa Catarina, Parará e Rio Grande do Sul, e da dificuldade em se deslocar para capitais e/ou cidades que oferecem cursos de mestrado profissional, favorecendo a inserção em cursos lato sensu.

A pesquisa de Ferreira et al. (2015), apesar de realizada com acadêmicos do mestrado profissional em Enfermagem, corrobora tais informações, uma vez que $95 \%$ dos participantes cursaram ou estavam cursando pós-graduação lato sensu e trabalhavam concomitantemente ao mestrado. Tais informações refletem os objetivos do mestrado profissional em capacitar profissionais com experiência, relacionando e aproximando teoria e prática. Cabe destacar que no referido estudo, assim como nos estudos de Guimarães (2018) e Maciel e Nogueira (2012), predominaram acadêmicos graduados nas mesmas áreas de formação do mestrado, mesmo constituindo-se como cursos que valorizam a interdisciplinaridade. Tal dado reforça o interesse dos mestrandos em permanecer em sua área de atuação, mas também em ampliar novas possibilidades de trabalho e se capacitar para o mercado de trabalho.

Não obstante os homens tenham respondido com maior frequência que o mestrado não se configurava ainda como uma opção quando estes cursavam a graduação, há mais participantes do sexo masculino cursando o mestrado profissional investigado. Observa-se que $50 \%$ dos mestrandos pesquisados ocupam cargos de gestão e/ou estratégicos, sendo que, segundo dados do IBGE (2018), em torno de 60,9\% dos cargos gerenciais no Brasil são ocupados por homens, que podem buscar o mestrado profissional em administração como uma estratégia de formação continuada. Ainda, verificou-se neste estudo que, ampliar a prática profissional foi apontada como expectativa antes de entrar no mestrado e ao término do mesmo, o que indica interesses em assumir novas posições na carreira.

As expectativas (antes e depois) em relação ao mestrado envolveram ampliar ou aprimorar a prática profissional, sendo que o desenvolvimento de competências se destacou como expectativa de carreira no momento do ingresso e o alcance de objetivos pessoais/profissionais surgiu como expectativa ao término do mestrado. Ao analisar as respostas relacionadas à prática profissional, constatou-se que o interesse pela docência foi o mais apontado, com 40 respostas. Os relatos de dois participantes, expressos no questionário, são exemplos das expectativas de mediação do mestrado profissional para a carreira acadêmica: "me abrir portas para ser professor da graduação"; "criar vínculo com a área de educação e com a área acadêmica, iniciar uma carreira na área de docência". Percebe-se que os mestrandos buscam novas possibilidades profissionais, refletindo na necessidade da autogestão na carreira (MAGALHÃES e BENDASSOLLI, 2013).

No entanto, cabe destacar que no estudo de Oliveira, Kilimnik e Oliveira (2013), com 22 gestores que realizaram a transição total ou parcial do mundo empresarial para a academia, verificou-se uma percepção idealizada da sala de aula como geradora de reconhecimento perene pelos alunos, assim como um espaço onde cumpre-se a missão de transformar o mundo para melhor por meio da educação dos jovens. Em alguns casos, segundo os autores, a escolha pela transição da gerência pela docência representou, inclusive, uma intenção de transição total de carreira.

Silveira (2016), Bujdoso (2009), Maciel e Nogueira (2012) verificaram a importância da docência para a maioria dos mestrandos e a crença de que o mestrado pode direcioná-los à vida acadêmica. Tal constatação também é corroborada por Campos e Guérios (2017), quando discutem a respeito da criação do primeiro mestrado profissional na área da Educação, no Brasil, em 2009, no Estado de Minas Gerais, e do constante aumento de cursos de mestrado profissional ao longo do território brasileiro. Cabe destacar que, no Brasil, em 2017 já havia 182 programas de pós-graduação (PPG) em Administração Pública e de Empresas, Ciências Contábeis e 
Turismo, distribuídos em 60 cursos de mestrados e doutorados integrados; dois doutorados isolados; 45 com somente mestrados acadêmicos; 73 mestrados profissionais; e dois mestrados profissionais em redes. Ao comparar estes dados, tanto dos cursos acadêmicos como profissionais, aos descritos nos anos de 2010 e 2013, houve o crescimento da área a altas taxas anuais, conforme apontado pelo Relatório da Avaliação Quadrienal da CAPES (MINISTÉRIO DA EDUCAÇÃO, 2017). Esse significativo aumento no número de programas de pós-graduação stricto sensu, acadêmicos e profissionais, revela uma crescente demanda por esse tipo de formação, que pode estar associada a expectativas de carreira nas áreas da docência e da pesquisa, mesmo tratando-se de mestrados profissionais.

Os dados mostraram que os participantes percebem o mestrado como uma possibilidade de ampliação na carreira e melhoria do desempenho na prática profissional. Essas informações são corroboradas por Oliveira, Amâncio Filho e Pinto (2014), ao afirmarem que o mestrado profissional vem se apresentando como uma alternativa para a solução da capacitação e qualificação de profissionais. Os relatos que seguem, de diferentes participantes do presente estudo, demonstram suas expectativas nesse sentido: "muito aprendizado para abrir portas e oportunidades profissionais"; "ser referência no tema dentro da empresa para projetos"; "poder desenvolver um trabalho que some às atuais atividades desenvolvidas". Tais expectativas indicam que o mestrado profissional representa novas possibilidades de carreira além na docência. Verifica-se a preocupação e necessidade de desenvolver competências em maior grau de complexidade, com vistas a assumir funções mais complexas. Em decorrência das exigências do mundo do trabalho ou da identificação de gaps de competências na formação inicial, o aumento pela procura de cursos de pós-graduação tem crescido exponencialmente, resultando na ampliação da oferta desses cursos (MAQUEZAN; SAVEGNAGO, 2020).

Suprir deficiências da graduação e desenvolver o raciocínio analítico também foram identificados como expectativas de mestrandos em relação aos seus respectivos programas de pós-graduação em estudos sobre o tema (BUJDOSO, 2009). Nessa direção, os mestrandos aqui investigados apontaram o desenvolvimento de competências como uma de suas expectativas ao ingressar no mestrado, principalmente no que se refere ao aprofundamento de conhecimentos, habilidades e atitudes que os auxiliem a vislumbrar novas oportunidades, estar mais preparados para os desafios profissionais e ampliar o networking, conforme relatam: "obter conhecimento em nível avançado sobre meu tema, conhecer a forma de produção de conhecimento científico"; "complementar as minhas habilidades enquanto pesquisador e profissional"; "estar mais relacionada com pessoas do ramo, além de compartilhar e receber conhecimento sobre as linhas de estudo". Essas expectativas relacionam-se ao desenvolvimento de competências técnicas (conhecimentos e habilidades), assim como de competências comportamentais (atitudes) e são ratificadas pelos dados da pesquisa de Oliveira (2014), na qual os recém-formados salientaram a necessidade de continuar os estudos, por meio da pós-graduação, para tornarem-se competitivos e favorecer a inserção no mundo do trabalho.

Estudos empíricos apontam que a motivação de alunos para a realização do mestrado profissional está ligada a descobrir e solucionar problemas dentro de suas áreas de atuação. Esses desafios estimulam cada vez mais os profissionais a continuarem se aperfeiçoando academicamente, de forma a desenvolver o conhecimento reflexivo e científico acerca de suas atividades. $\mathrm{O}$ mestrado se torna uma oportunidade para estas realizações e para o contínuo aprimoramento profissional (FERREIRA et al., 2015). Nessa perspectiva, egressos de um mestrado profissional em Administração revelaram o desenvolvimento do pensamento crítico, a capacitação/preparação na maneira de liderar e a ampliação da rede de relacionamentos como principais expectativas quanto ao mestrado (GUIMARÃES, 2018).

Em relação aos objetivos de vida e carreira que os participantes do presente estudo pretendem alcançar por intermédio do mestrado profissional em Administração, os relatos incluíram questões financeiras, como aumentar a renda mensal, "realizações particulares" e, inclusive, cursar futuramente o doutorado, em razão do interesse pela docência já mencionado. Guimarães (2018) aponta que muitos ingressantes no mestrado profissional o fazem para alcançar alguns objetivos pessoais, como aprimorar 
o currículo, ampliar seu networking e o retorno financeiro. Silva (2015) confirma essa perspectiva, ao ressaltar que muitos recém-formados ingressam em programas de mestrado com o objetivo de obter reconhecimento financeiro em suas áreas de atuação, mas também com o desejo de continuar a se aperfeiçoar academicamente.

As concepções sobre sucesso na carreira dos mestrandos investigados revelaram a predominância da dimensão subjetiva, já indicada na Tabela 3, que pode ser verificada por meio de respostas tais como: "gostar do que faz"; "ser feliz onde atua, poder ajudar e ser ajudado"; "levantar animado, tomar banho e ir à luta"; "ser reconhecido pelos funcionários e executivos como um líder em solução de problemas do dia a dia"; "estar em paz com corpo, mente e espírito"; "curtir a família e ter qualidade de vida”. Quanto à dimensão objetiva, as respostas envolveram sobretudo questões financeiras, por exemplo: "retorno financeiro suficiente para suprir os objetivos de vida"; "remuneração compatível"; "ter condições de sustentar a mim e a minha família”. Constata-se que as duas dimensões, associadas ao sucesso na carreira, representam valores pessoais e profissionais dos mestrandos investigados. No entanto, a prevalência por aspectos subjetivos denota questões relacionadas a propósito de vida e à percepção de que o trabalho é uma esfera da vida que deve gerar satisfação e prazer, assim como o lazer e os momentos com a família, por exemplo. Cabe destacar que Oliveira et al. (2019), Carvalho (2014), Ferreira (2016) e Rodrigues (2016) encontraram dados semelhantes em seus próprios estudos. No estudo de Oliveira et al. (2019), recém graduados apontaram como aspectos subjetivos, relacionados à percepção de sucesso da carreira, a superação de medos e incertezas, a construção de confiança no futuro, o compromisso com o progresso de metas e planos de carreira, a construção da identidade profissional, a adequação ao trabalho e a satisfação com a carreira. Quanto aos critérios objetivos, foram indicados a conquista de um emprego na área da graduação com bom salário, a independência financeira e o reconhecimento no trabalho associado a promoções, prêmios e indicações.

Carvalho (2014) verificou que professores valorizam mais a contribuição com o aprendizado de seus alunos e a sensação de conquista do que a remu- neração, uma vez que professores de ensino médio e fundamental são, segundo os entrevistados, mal pagos. Ferreira (2016) constatou que as expectativas de carreira de servidores públicos indicam quesitos sobre ter qualidade de vida, equilibrar a vida pessoal com o trabalho, ter prestígio entre os colegas, realizar um trabalho que goste, satisfação com o rumo da carreira e ter uma carga de trabalho menor, em oposição a critérios objetivos como os financeiros.

Já Rodrigues (2016) concluiu que os médicos demonstraram satisfação muito maior com os aspectos subjetivos da profissão, como realização pessoal, equilíbrio entre trabalho e lazer, integração social no trabalho e ser feliz, do que com fatores objetivos como salários compatíveis, hierarquias e promoções. Zhang et al. (2018) constataram em seu estudo que a incivilidade e problemas com colegas de trabalho podem trazer um alto grau de insatisfação com o trabalho. Assim sendo, de acordo com os autores, pode-se inferir que, independentemente dos aspectos objetivos, quando não se alcança os subjetivos mínimos necessários, a carreira dificilmente será considerada de sucesso por esses profissionais. Estes dados são semelhantes aos do estudo de Vieira e Coimbra (2006), no qual se constatou a predominância dos critérios subjetivos (55\%) face aos critérios objetivos (45\%).

Baglama e Uzunboylu (2017) apontaram que a autoeficácia nas decisões de carreira de professores de educação especial tem sido mais relevante que aspectos salariais no contexto de sucesso profissional. Frenkel e Bednall (2016), por sua vez, indicaram que o suporte organizacional, como as oportunidades de promoções, justiça organizacional e expectativas positivas sobre os funcionários, tornam-se impulsionadores para a utilização de competências atitudinais dentro da organização, inferindo-se assim que a combinação de fatores objetivos e subjetivos é motivadora e pode ser interpretada como sucesso profissional.

Tendo em vista que concepções a respeito de sucesso na carreira são resultantes da relação entre valores, escolhas, expectativas individuais e determinações sociais mais amplas (OLIVEIRA et al., 2019), pertencer a determinada geração, entre outras características sociodemográficas, pode explicar, em parte, os achados de investigações sobre o tema. Fantini e Souza (2015) explicam que "geração" é um conceito que classifica o conjunto de indivíduos nascidos em 
uma mesma época, que apresentam determinados comportamentos, valores e motivações, influenciados por um contexto histórico, acontecimentos sociais e culturais. Nesse sentido, as autoras constataram, junto a profissionais de diversos ramos de atuação, que as gerações baby boomers (nascidos entre 1946-1964), X (nascidos entre 1965-1980) e Y (nascidos entre 19802000) preferem uma carreira com maior estabilidade e segurança, enquanto a geração $Z$ (nascidos a partir de 2000) opta por autonomia e uma carreira sem fronteiras organizacionais. No entanto, neste estudo não foram encontradas tais diferenças entre as gerações, cujas informações sinalizaram que as expectativas dos mestrandos sobre carreira, e especificamente suas percepções sobre sucesso na carreira, concentraram-se na dimensão subjetiva. Todavia, cabe destacar que além da maioria dos respondentes $(51,6 \%)$ pertencer a geração Y, a maioria $(88,2 \%)$ trabalha. Tais dados devem ser considerados, uma vez que a prioridade dada a valores relacionados à satisfação, ao bem-estar e à felicidade no trabalho, quando comparados à estabilidade è̀ segurança, pode ser influenciada pelo fato de já estarem inseridos no mercado de trabalho e atuando profissionalmente.

\section{CONSIDERAÇÕES FINAIS}

O objetivo do referido estudo foi analisar as expectativas dos acadêmicos de um programa de mestrado profissional em Administração em relação à entrada e término do mestrado e suas concepções sobre sucesso na carreira. Além disso, buscou verificar possíveis associações entre variáveis de carreira e variáveis sociodemográficas e educacionais. na amostra. Os participantes foram, em sua maioria, profissionais do sexo masculino, casados ou em união estável, graduados em cursos da área de Ciências Sociais Aplicadas, cuja atuação envolve cargos gerenciais e estratégicos.

As principais expectativas dos respondentes em relação à entrada no mestrado envolveram o desenvolvimento de competências e o aprimoramento da prática profissional, com destaque ao aprofundamento de conhecimentos e ampliação de experiências relacionadas às áreas nas quais se graduaram. Expectativas associadas ao desenvolvimento de competências comportamentais também foram contempladas. No que se refere às expectativas de carreira relacionadas ao momento de término do mestrado, os acadêmicos pesquisados indicaram novamente questões vinculadas à prática profissional, tais como a ampliação das oportunidades profissionais por meio do networking, e expectativas associadas ao alcance de determinados objetivos de vida, como o interesse pela prática docente associada à realização pessoal e profissional. Tais achados sugerem a necessidade da autogestão na carreira com base em seus projetos de vida e trabalho, como respostas ao crescimento dos contratos psicológicos transacionais (de curto tempo) e idiossincráticos (personalizados) estabelecidos entre trabalhadores e organizações. Também, a percepção da necessidade de desenvolver novas competências técnicas e interpessoais, como forma de suprir as exigências impostas pelo mundo de trabalho e as deficiências da graduação.

Assim sendo, os participantes entendem que a teoria alinhada à prática, proposta pelos cursos de mestrado profissional como uma modalidade de formação continuada, favorece o desenvolvimento e a transição de carreira, seja na progressão profissional nas próprias organizações nas quais atuam, seja na inserção em novas carreiras, incluindo a docência. Dessa forma, o mestrado profissional cumpre sua função de aproximar a academia do mundo do trabalho, como indicado pelos estudos sobre o tema, favorecendo a construção, a ampliação e a ressignificação de conhecimentos profissionais e acadêmicos.

Os profissionais investigados destacaram sua busca por possibilidades de trabalho diferenciadas, que não gerem apenas ganhos financeiros, mas também felicidade e satisfação no trabalho. Essa compreensão leva-os a questionar suas relações com o trabalho e a identificar desafios que precisam enfrentar. À vista disso, a grande maioria dos participantes interpretou sucesso na carreira evidenciando exclusivamente sua dimensão subjetiva, como ajudar pessoas, adquirir conhecimentos abrangentes e se desenvolver pessoalmente, ou associando a dimensão subjetiva com a objetiva, que envolve, por exemplo, estabilidade no emprego e retorno financeiro. Considera-se que esse resultado pode ter sido influenciado pelo fato de muitos participantes já estarem inseridos no mundo do trabalho, provavelmente com certa esta- 
bilidade, possuírem especialização e ocuparem cargos ou realizarem trabalhos normalmente associados à prestígio profissional e salários mais elevados.

Quanto às gerações, o predomínio das gerações $\mathrm{Y}$ e X entre os mestrandos investigados revela a preocupação de adultos maduros em se preparar para as transformações no mundo do trabalho, cada vez mais fluido, incerto e exigente quanto ao desenvolvimento de competências profissionais, sinalizadas pelos respondentes como expectativas em relação ao mestrado profissional. Portanto, entendem a formação continuada como uma estratégia de desenvolvimento de carreira vinculada aos seus projetos de vida. Por sua vez, a existência de jovens profissionais da geração $\mathrm{Z}$ cursando mestrado profissional demonstra que essa modalidade de pós-graduação stricto sensu também surge como uma opção de carreira ao término da graduação.

Observa-se que o fato de associações significativas entre as variáveis de carreira estudadas e variáveis sociodemográficas e educacionais não terem sido constatadas pode estar relacionado ao tamanho da amostra, constituindo-se como uma limitação deste estudo. Assim, recomenda-se que novos estudos sobre carreira com amostras maiores de pós-graduandos em cursos de mestrado profissional em Administração sejam efetivados, para constatar se os resultados encontrados na presente pesquisa são confirmados ou se o gênero, a idade, o sexo, a formação educacional e a posição profissional encontram-se de alguma forma associados a expectativas de carreira e a concepção de sucesso na carreira de mestrandos. A segunda limitação envolve o fato de os respondentes não cursarem o mesmo período do curso, na ocasião da coleta. Desta forma, sugere-se que mestrandos iniciantes, intermediários e finalistas poderão apresentar diferentes expectativas de carreira, o que indica novos estudos comparativos com este público, objetivando verificar a influência do mestrado nas expectativas de carreira dos acadêmicos.

Considerando a atualidade e a relevância científica e social do tema, sugere-se, ainda, a realização de estudos com métodos qualitativos e quantitativos, que busquem compreender, a partir da perspectiva do desenvolvimento de carreira e da formação continuada, os motivos que levam profissionais da área das Ciências Sociais Aplicadas a escolherem o mestrado profissional em Administração como forma de mediação para a carreira acadêmica. Como no presente estudo a maior parte dos mestrandos já se encontra inserida no mercado de trabalho, a escolha pelo mestrado profissional pode estar vinculada a probabilidade de associar o trabalho como docente a outras atividades profissionais, configurando-se como uma transição parcial de carreira. Contudo, também existe a possibilidade da decisão pela transição total de carreira, do mundo empresarial para o acadêmico, como indicada por outros estudos. Pesquisas sobre as expectativas de carreira e concepções de sucesso na carreira de alunos de cursos de pós-graduação stricto sensu de diferentes gerações e distintas universidades, públicas e particulares, também são recomendadas.

\section{REFERÊNCIAS}

ABRAHAMSEN, B. A longitudinal study of nurses' career choices: The importance of career expectations on employment in care of older people. Journal of Advanced Nursing, [S.1.], v. 75, n. 2, p. 348-356, 2019. DOI: https://dx.doi.org/10.1111/jan.13847

ALMEIDA, A. N. et al. Imersão internacional: uma avaliação de intercambistas de mestrado profissional. Revista Gestão Universitária na América Latina, Florianópolis, v. 10, n. 1, p. 280 301, fev. 2017. Disponível em: https://periodicos. ufsc.br/index.php/gual/article/view/19834535.2017v10n1p280. Acesso em: 23 ago. 2020. DOI: https://doi.org/10.5007/1983-4535.2017v10n1p28

\section{ALSTON, M. J. et al. Career expectations of obstetrics and gynecology residents and future residents. Obstetrics \& Gynecology, [S.1.], v. 132, 2018. Suplemento 1. DOI: https://dx.doi.org/10.1097/ AOG.0000000000002817}

BAGLAMA, B.; UZUNBOYLU, H. The relationship between career decision-making-self-efficacy and vocational outcome expectations of preservice special education teachers. South African Journal of Education, [S.1.], v. 37, n. 4, p. 1-11, 2017. 
BARDIN, L. Análise de conteúdo. Lisboa: Edições 70, 2016.

BARROS, L. E. V.; CAPPELLE, M. C. A.; GUERRA, P. Symbolic interactionism and career outsider: a theoretical perspective for career study. Revista Eletrônica de Administração, Porto Alegre, v. 25, n. 1, p. 26-48, abr. 2019. Disponível em: http://www. scielo.br/scielo.php?script=sci_arttext\&pid=S141323112019000100026\&lng=pt\&nrm=iso. Acesso em: 16 ago. 2020.

BENDASSOLLI, P. F. Recomposição da relação sujeito-trabalho nos modelos emergentes de carreira. Revista de Administração de Empresas, São Paulo, v. 49, n. 4, p. 387-400, dez. 2009. Disponível em: http://www.scielo.br/scielo.php?script=sci_ arttext\&pid $=$ S0034-75902009000400003\&lng=pt\& nrm=iso. Acesso em: 16 ago. 2020.

BONASSI, T.; WOLTER, S. C. Measuring the success of transition: The results of a pre-study in Switzerland. Education \& Training, [S.1.], v. 44, n. 4/5, p. 199-207, 2002.

BRASIL. Portaria Normativa No 47, de 17 de outubro de 1995. Dispõe sobre a determinação da implantação, recomendação, avaliação cursos de mestrado dirigidos à formação profissional. Diário Oficial da União, Brasília, DF, 17 out. 1995.

BRASIL. Portaria Normativa No 80 , de 16 de dezembro de 1998. Dispõe sobre o reconhecimento dos mestrados profissionais e dá outras providências. Diário Oficial da União, Brasília, DF, 16 dez. 1998.

BRASIL. Portaria Normativa No 389, de 23 de março de 2017. Dispõe sobre o mestrado e doutorado profissional no âmbito da pós-graduação stricto sensu. Diário Oficial da União: seção 1, Brasília, DF, n. 58, p. 61, 23 mar. 2017.

\section{BUJDOSO, Y. L. V. Pós-graduação stricto sensu:} busca de qualificação profissional ou suporte frente às vicissitudes do mundo do trabalho. 2009. Tese (Doutorado em Medicina) - Faculdade de Medicina, Universidade de São Paulo, São Paulo, 2009.
CAMPOS, M. A. T.; GUÉRIOS, E. Mestrado profissional em educação: reflexões acerca de uma experiência de formação à luz da autonomia e da profissionalidade docente. Educar em Revista, Curitiba, v. 63, p. 35-51, 2017.

CARVALHO, C. P. As necessidades e expectativas das professoras-estudantes da Pedagogia/PARFOR sobre sua formação docente frente os desafios da prática profissional. 2014. Dissertação (Mestrado em Educação) - Universidade Católica de Santos, Santos, 2014.

CRESWELL, J. W. Projeto de pesquisa: métodos qualitativo, quantitativo e misto. 2. ed. Porto Alegre: Artmed, 2007.

DRIES, N. The meaning of career success: Avoiding reification through a closer inspection of historical, cultural and ideological contexts. Career Development International, [S.1.], v. 16, n. 4, p. 364384, 2011.

FANTINI, C.; SOUZA, N. C. Análise dos fatores motivacionais das gerações baby boomers, $\mathrm{X}, \mathrm{Y}$ e Z e as suas expectativas sobre carreira profissional. Revista IPecege, [S.1.], v. 1, n. 3/4, p. 126-145, 2015.

FERREIRA, P. C. G. Nova geração de servidores públicos federais: valores, expectativas, comprometimento organizacional e intenção de rotatividade. 2016. Dissertação (Mestrado em Economia) - Universidade de Brasília, Brasília, DF, 2016.

FERREIRA, R. E. et al. O perfil dos alunos do mestrado profissional no ensino da saúde. Revista de Pesquisa Cuidado é Fundamental Online, [S.1.], v. 7, n. 4, p. 3554-3562, 2015.

FIELD, A. Descobrindo estatísticas usando o SPSS.

3. ed. Londres: Sage Publications Ltd., 2009. 
FRENKEL, S. J.; BEDNALL, T. How training and promotion opportunities, career expectations, and two dimensions of organizational justice explain discretionary work effort. Human Performance, [S.1.], v. 29, n. 1, p. 16-32, 2016.

GEOCAPES. Sistema de Informações Georreferenciadas da CAPES - Indicadores. [S.1.], 2020. Disponível em: https://geocapes.capes.gov.br/ geocapes/. Acesso em: 6 fev. 2020.

GEREMIA, H. C.; LUNA, I. N.; SANDRINI, P. R. A escolha de psicólogos em cursar mestrado em Psicologia. Psicologia: Ciência e Profissão, Brasília, DF, v. 35, n. 3, p. 676-693, set. 2015. DOI: http:// dx.doi.org/10.1590/1982-3703001142013. Disponível em: http://www.scielo.br/scielo.php?script=sci_ arttext\&pid $=$ S1414-98932015000300676\&lng=pt \&nrm=iso. Acesso em: 16 ago. 2020. http://dx.doi. org/10.1590/1982-3703001142013.

GU, J.; LEVIN, J.; LUO, Y. Reproducing "academic successors" or cultivating "versatile experts": Influences of doctoral training on career expectations of Chinese PhD students. Higher Education, [S.l.], v. 76, p. 427-447, 2018. DOI: http://dx.doi.org/10.1007/ s10734-017-0218-X.

GUIMARÃES, R. M. Fatores decisivos na escolha dos programas de mestrados profissionais em administração (MPA): uma análise sob a ótica dos egressos. 2018. Dissertação (Mestrado Profissional Executivo em Gestão Empresarial) - Fundação Getúlio Vargas, Rio de Janeiro, 2018.

HAN, J. et al. Career expectations and preferences of Urology Residency Applicants. Urology, [S.l.], v. 123, p. 44-52, 2019. DOI: https://doi.org/10.1016/j. urology.2018.07.071

HENSTRA, D.; MCGOWAN, R. Millennials and public service: An exploratory analysis of graduate student career motivations and expectations. Public Administration Quarterly, [S.l.], v. 40, n. 3, p. 78104, 2016.
INSTITUTO BRASILEIRO DE GEOGRAFIA E ESTATÍSTICA - IBGE. Estatísticas de gênero: Indicadores sociais das mulheres no Brasil. Estudos e Pesquisas Informação Demográfica e Socioeconômica, [S.1.], v. 38, p. 1-13, 2018. Disponível em: https://biblioteca.ibge.gov.br/visualizacao/livros/ liv101551_informativo.pdf. Acesso em: 18 jan. 2020.

KRAKAUER, P. V. C.; MARQUES, J. A.; ALMEIDA, M. I. R. O que esperar da dissertação de mestrado profissional em Administração? Revista Gestão Universitária na América Latina, Florianópolis, v. 11 , n. 2, p. 23-46, maio 2018. DOI: http://dx.doi. org/10.5007/1983-4535.2018v11n2p23

LENT, R. W. et al. Sappington Sources of self-efficacy and outcome expectations for career exploration and decision-making: A test of the social cognitive model of career self-management. Journal of Vocational Behavior, [S.1.], v. 99, p. 107-117, 2017.

LIBERMAN, F. et al. Articulação prático-teórica e a produção de inovação no mestrado profissional em Ensino em Ciências da Saúde. Saúde e Sociedade, São Paulo, v. 24, n. 2, p. 716-729, abr./ jun. 2015. DOI: https://dx.doi.org/10.1590/S010412902015000200025 Disponível em: http://www. scielo.br/scielo.php?script=sci_arttext\&pid=S0104$12902015000200716 \& \operatorname{lng}=\mathrm{en} \& \mathrm{nrm}=\mathrm{iso}$. Acesso em: 23 ago. 2020.

MACIEL, R. G. A.; NOGUEIRA, H. G. P. Mestrado profissional: desenvolvimento pessoal e profissional. Revista Brasileira de Pós-Graduação, Brasília, DF, v. 9, n. 17, p. 461-487, 2012.

MAGAlHÃES, M. O.; BENDASSOLLI, P. F. Desenvolvimento de carreira nas organizações. In: BORGES, L. O.; MOURÃO, L. (Org.). O trabalho e as organizações: atuações a partir da psicologia. Porto Alegre: Artmed, 2013. p. 433-464. 
MAMEDE, W.; ABBAD, G. S. Objetivos educacionais de um mestrado profissional em saúde coletiva: avaliação conforme a taxonomia de Bloom. Educação e Pesquisa, São Paulo, v. 44, p. 1-21, 2018. DOI: https://dx.doi.org/10.1590/s16784634201710169805 Disponível em: http://www. scielo.br/scielo.php?script=sci_arttext\&pid=S151797022018000100309\&lng $=$ en $\&$ nrm $=$ iso. Acesso em: 23 ago. 2020.

MARQUEZAN, L. P.; SAVEGNAGO, C. L. O mestrado profissional no contexto da formação continuada e o impacto na atuação dos profissionais da educação. Revista Internacional de Educação Superior, Campinas, v. 6, p. 1-22, 2020.

\section{MATTOS, V. Pós-graduação em tempos de} precarização do trabalho: alongamento da escolaridade e alternativa ao desemprego. São Paulo: Xamã, 2011.

MINISTÉRIO DA EDUCAÇÃO. Coordenação de Aperfeiçoamento de Pessoal de Nível Superior. Relatório da Avaliação Quadrienal: Administração Pública e de Empresas, Ciências Contábeis e Turismo. [S.1.], 2017. Disponível em: https://www.capes.gov. $\mathrm{br} /$ images/stories/download/avaliacao/relatoriosfinais-quadrienal-2017/20122017-Administracaoquadrienal.pdf. Acesso em: 21 ago. 2020.

NG, T. W. H.; FELDMAN, D. C. Subjective career success: A meta-analytic review. Journal of Vocational Behavior, [S.1.], v. 85, n. 2, p. 169-179, 2014.

NÓBREGA, M. H. Mestrado profissional em Letras e tecnologia educacional. EntreLetras, Araguaína, v. 9, n. 3, p. 52-68, out./dez. 2018. DOI: https://dx.doi. org/10.20873/uft.2179-3948.2018v9n3p52

OLIVEIRA, L. C. V.; KILIMNIK, Z. M.; OLIVEIRA, R. P. Da gerência para a docência: metáforas do discurso de transição. Revista Eletrônica de Administração, Porto Alegre, v. 19, n. 2, p. 301-329, ago. 2013. Disponível em: http://www. scielo.br/scielo.php?script=sci_arttext\&pid=S1413$23112013000200002 \& \operatorname{lng}=\mathrm{pt} \& \mathrm{nrm}=$ iso. Acesso em: 16 ago. 2020.
OLIVEIRA, M. C. Sucesso na carreira depois da graduação: estudo longitudinal prospectivo da transição universidade-trabalho. 2014. Tese (Doutorado em Psicologia) - Faculdade de Filosofia, Ciências e Letras de Ribeirão Preto, Universidade de São Paulo, Ribeirão Preto, 2014.

OLIVEIRA, M. C. et al. Career success according to new graduates: implications for counseling and management. Paidéia, Ribeirão Preto, v. 29, p. 1-9, 2019. Disponível em: http://www.scielo.br/scielo. php? script=sci_arttext\&pid=S0103-863X20190001 00402\&lng=pt\&nrm=iso. Acesso em: 16 ago. 2020.

OLIVEIRA, S. P.; AMÂNCIO FILHO, A.; PINTO, I. V. Características e expectativas dos inscritos no processo seletivo do mestrado profissional em Gestão do Trabalho e da Educação na Saúde. Revista Brasileira de Pós-Graduação, Brasília, DF, v. 11, n. 24, p. 589-603, 2014.

PAIXÃO, R. B.; HASTENREITER FILHO, H. N. Autoavaliação de impactos: O que nos dizem os egressos de um mestrado profissional em Administração? Administração: Ensino e Pesquisa, Rio de Janeiro, v. 15, n. 4, p. 831-859, out./dez. 2014.

RADÜNZ, R. Mestrado Profissional em História: o desafio do trabalho de conclusão final do curso. Revista OPSIS, Catalão, v. 15, n. 1, p. 149-163, 2015.

RICHARDSON, R. J. Pesquisa social: métodos e técnicas. 3. ed. São Paulo: Atlas, 1999.

RODRIGUES, C. L. M. M. A relação entre percepção de sucesso na carreira e qualidade de vida no trabalho: um estudo comparativo com médicos que atuam na cidade de Belo Horizonte. 2016. Dissertação (Mestrado em Administração) - Faculdade de Ciências Empresariais, Universidade FUMEC, Belo Horizonte, 2016.

SAMPIERI, R. H.; COLLADO, C. F.; LUCIO, M. P. B. Metodología de la investigación. 5. ed. México: McGraw-Hill, 2010. 
SANTOS, M. B. Pesquisa ou desenvolvimento profissional de professores no mestrado profissional em Letras? EntreLetras, Araguaína, v. 9, n. 3, p. 7-32, out./dez. 2018. DOI: http://dx.doi.org/10.20873/ uft.2179-3948.2018v9n3p7

SAVICKAS, M. L. Life design: A paradigm for career intervention in the 21st century. Journal of Counseling \& Development, [S.1.], v. 90, n. 1, p. 13-19, 2012.

SCOCHI, C. G. S. et al. Mestrado profissional: potencial contribuição para a Enfermagem de Prática Avançada. Revista Brasileira de Enfermagem, Brasília, DF, v. 68, n. 6, p. 1186-1189, nov./dez. 2015. DOI: http://dx.doi. org/10.1590/0034-7167.2015680626i

SEWAYBRICKER, L. E. Carreira sem Fronteiras: Limite e Aplicabilidade de uma Teoria Clássica. Psicologia: Ciência e Profissão, Brasília, DF, v. 38, n. 1, p. 129-141, mar. 2018. Disponível em: http://www. scielo.br/scielo.php?script=sci_arttext $\&$ pid $=$ S1414$98932018000100129 \& \operatorname{lng}=\mathrm{pt} \& \mathrm{nrm}=\mathrm{iso}$. Acesso em: 16 ago. 2020.

SILVA, B. D.; MARQUES, M. F. (2001). Trajectórias de inserção profissional dos licenciados em Educação pelo Instituto de Educação e Psicologia da Universidade do Minho. In: GONÇALVES, L. S.; VASCONCELOS, R.; CAIRES, S. (Org.). Da Universidade para o Mundo do Trabalho: Desafios para um diálogo. Braga: Universidade do Minho. p. 205-226.

SILVA, C. K. L. A intersubjetividade dos professores que cursam mestrado e doutorado na Universidade Tecnológica Intercontinental, UTIC de sua vida profissional docente: Um estudo qualitativo ano de 2014, Assunção, Paraguai. Revista Internacional de Apoyo a la Inclusión, Logopedia, Sociedad y Multiculturalidad, [S.1.], v. 3, n. 4, p. 87-105, out. 2017.
SILVA, M. Z.; ANDRADE, A. L. Influência da carreira e do capital psicológico em aspectos de vida e trabalho. Psico-USF, Campinas, v. 24, n. 1, p. 55-67, jan. 2019. Disponível em: http://www. scielo.br/scielo.php?script=sci_arttext\&pid=S1413$82712019000100055 \& \operatorname{lng}=\mathrm{pt} \& \mathrm{nrm}=\mathrm{iso}$. Acesso em: 16 ago. 2020.

SILVA, T. S. Expectativas de carreira e experiências de inserção no mercado de trabalho: estudo com formandos e egressos do curso de Administração. 2015. Dissertação (Mestrado em Administração) Universidade de Taubaté, Taubaté, 2015.

SILVEIRA, A. C. Expectativas, estratégias e alcances de inserção profissional dos estudantes cotistas e não cotistas da Universidade Federal da Bahia (UFBA). 2016. Tese (Doutorado em Educação) Faculdade de Educação, Universidade Federal da Bahia, Salvador, 2016.

VAN DER WEIJDEN, I. et al. Career satisfaction of postdoctoral researchers in relation to their expectations for the future. Higher Education, [S.1.], v. 72, p. 25-40, 2016. DOI: https://dx.doi.org/10.1007/ s10734-015-9936-0

VIEIRA, D.; COIMBRA, J. L. Sucesso na transição escola-trabalho: A percepção de finalistas do ensino superior português. Revista Brasileira de Orientação Profissional, São Paulo, v. 7, n. 1, p. 1-10, 2006.

ZHANG, S. et al. Impact of workplace incivility in hospitals on the work ability, career expectations and job performance of Chinese nurses: a cross-sectional survey. BML Open, [S.1.], v. 8, n. 12, 2018. 